\title{
Lead Poisoning in Pediatric Groups: A Global Burden of Disease
}

\section{$A B$ Adeyiga*}

\author{
Department of Medical Biochemistry, Nile University of Nigeria, Abuja, Nigeria
}

*Corresponding author: Adeyiga Bukunayo Adeseye, Department of Medical Biochemistry, Nile University of Nigeria, FCT, Abuja, Nigeria

\begin{abstract}
Background: Lead poisoning is a major public health issues that affect pediatric age group with different multi-organ damage. In children for instance, it has been discovered that there is no small level or appreciable quantity of lead exposure that is safe for children because of developmental growth and cognitive development at this very crucial stage of life. Children are at very high risk because of their handto-mouth explorative behaviors at this developmental age thereby leading to unintentional ingestion of lead. Persistent exposure to lead has been attributed to difficulty in learning, low intelligence quotient (LIQ), attention deficit and behavioral problems. Even at low levels of lead poisoning, accumulating lines of evidence show an irreversible, deleterious effect on a child's development that result in learning and behavioral disorders with diminished attention span. In addition, the affected patient present with clinical symptoms ranging from abdominal pain, loss of appetite, renal function impairment, and anemia due to inhibition of synthesis of oxygen carrying protein called hemoglobin. Moreover, childhood disease of lead poisoning could develop into neurodegenerative diseases such as Parkinson's disease and Alzheimer's disease due to epigenetic modification in future.
\end{abstract}

Methods: Literature search strategy was used through electronic data bases, by using PubMed, Google Scholar, and Medline between years 1960 to year 2019. The search strategy that was used is "lead poisoning in children" or "blood toxicity of lead in childhood". The literature quality was assessed by selecting articles that were relevant to the topic of my discussion based on the standard of Agency for Healthcare Research and Quality (AHRQ). In the search 2778 articles were got. Out of the research results obtained, only relevant articles were selected for the purpose of topic being studied.

Results: In the view of the evidences above, lead poisoning and toxicity among pediatric group are a global burden of disease because of the emergent industrial activities in the world today.

Conclusion: The aim of this review study is to determine the effect of lead toxicity among pediatric age group and its social burden on affected children with possible policy and education awareness to mitigate this menace.

\section{Keywords}

Lead poisoning, Oxidative stress, Biochemical metabolism of lead, Anemia, Neurotoxicity

\section{Introduction}

Lead metal being an environmental pollution with toxic effect, its low quantity in the blood has been associated with a serious deleterious effect. It has been described to be a toxic heavy metal that can cause damage to human organs and their tissue system, particularly during the development of central nervous system (CNS). Most importantly, exposure to lead has been attributed to difficult in learning, low intelligence quotient (LIQ), attention deficit andbehavioral problems among children of younger age [1]. Even low level of lead poisoning has been shown to be associated with irreversible, deleterious effects on a child's development leading to learning [2] and behavioral disorders with tendency to crime commission. It has been discovered that children absorbed about $50 \%$ of ingested lead compared to adult with about $20 \%$ of ingested lead. This could account for some of the higher degree of deleterious effect presented in the affected children. The half-life of lead in adult body is estimated to be 28 days. In pediatric group, there is no known information supporting the half-life of ingested lead. Recently, hearing impairment with decreased intelligence quotient (IQ), and diminished attention span have been a major concern of environmental health care provider [3]. At high levels, lead poisoning can cause convulsions, coma, and even death [4]. Poisoning is an important mode of accidental injury in the pediatric age group that is associated with significant mortality and morbidity.Of worth noting, large majority of children

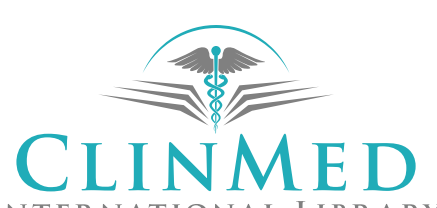

Citation: Adeyiga AB (2021) Lead Poisoning in Pediatric Groups: A Global Burden of Disease. Int J Pediatr Res 7:083. doi.org/10.23937/2469-5769/1510083

Accepted: December 15, 2021: Published: December 17, 2021

Copyright: (c) 2021 Adeyiga AB. This is an open-access article distributed under the terms of the Creative Commons Attribution License, which permits unrestricted use, distribution, and reproduction 
Table 1: Ways and source of exposure to lead poisoning.

\section{Environmental sources}

1. Interior or exterior paint, old putty, interior plaster, exterior decorative infrastructure (e.g., 'faux pewter' fencing)

\section{Household lead-laden dust}

3. Soil

4. Drinking water; household lead plumbing, standpipes, water mains, faucets, lead-soldered pipes

5. Parental occupations 'Take-Home' Lead (examples include 12. Herbs and dietary supplements: Imported herbal construction, renovation, and demolition work, lead-paint products; dietary supplements (e.g. calcium); imported abatement, pipe fitting and plumbing, battery manufacturing, spices (e.g. turmeric); candy from Mexico (the ingredient mining, ship building or other marine work, e-scrap recycling)

6. Hazardous neighborhoods: homes located near lead-smelters, 13. Soldering cans for beverages mining, nearby homes undergoing demolition, toxic waste sites, homes under bridges, homes near incinerators, battery recycling facilities

7. Home renovations Novelty jewelry, charms, medallions Burning 14. Plants cultivated in lead contaminated soil for human painted wood indoors Some imported toys, crayons, pewter consumption

figurines Antique cribs or furniture Aviation gasoline ('Avgas' for

small piston engine planes

toys produced nowadays have been reported to contain a higher percentage of lead constituent that has a significant damaging effect on children between the ages of 1-11 years [5-7]. Currently, there is no known low level of blood lead in pediatric children that could establish the diagnosis of lead poisoning and toxicity $[8,9]$. What this review tends to establish is the need for proactive method of diagnosis in pediatric age group with timely monitor to blood level of lead among this population group. Importantly, it will be a burden lifting economically and socially by considering blood lead level a routine medical laboratory test due to high rate of industrial production of lead containing products, contaminated sea foods and contamination of food substance via food agricultural produce from already adulterated soil from plants and crops as could be seen in Table 1.

Consequence to the individual harm associated with lead poisoning, the society as a whole bears a great social and economic burden. The diagnosis in children is based on blood lead level (BLL). By American Academy of pediatrics, lead poisoning can be established by blood lead level of $10 \mu \mathrm{g} / \mathrm{dl}$ or above $10 \mu \mathrm{g} / \mathrm{dl}$ [10]. In accordance with the works of Min-Ming Li and his colleagues, it has been argued that there is a strong correlation between economic status of the affected children and lead poisoning often seen among the pediatric age groups. The major obstacle to prevention of lead poisoning is lack of awareness and proper public education as to the damage that could be caused by lead ingestion through various ways of human activities (Table 1). Lead poisoning prevention can be achieved by an intense awareness through clinician-scientists in the rural and industrial areas because their works get publicized and get promoted with less effort [11]. Moreover, there is a long history of public exposure to lead in foods and drinks consumed by human. In the early $19^{\text {th }}$ and $20^{\text {th }}$ centuries, lead poisoning became common among workers with whose occupational works revolves around smelting, painting, printing, and many other industrial activities (Table 1 ).

\section{Materials and Methods}

Literature search strategy was used through electronic data bases, by using PubMed, Google Scholar, and Medline between years 1960 to year 2019. The search strategy that was used is "lead poisoning in children" or "blood toxicity of lead in childhood". The literature quality was assessed by selecting articles that were relevant to the topic of my discussion based on the standard of Agency for Healthcare Research and Quality (AHRQ). In the search 2,778 articles were got. Only relevant articles were selected based on their importance to the topic of discussion.

\section{Pathophysiology of lead and its metabolism}

Lead is an environmental toxin found virtually every that has the capacity of causing damaging effect to brain of developing children [12]. The absorption of lead has been seen to be based onvarying degree of factors such as the particulate size, age of individual, route of exposure, health of individual and its nutritional status. There are still some nuances to the mechanism of action on how lead induced toxicity causes damage to various tissue organs. Among the recognized molecular mechanismsis the oxidative stress induction, direct apoptic process activation on neuronal cells, interference on $\mathrm{Ca}^{2+}$ dependent enzymes and $\mathrm{Ca}^{2+} /$ calmodulin signaling pathway [13]. The molecular mechanism of lead induced 
Elevated levels of Lead $\left(\mathrm{Pb}^{2+)}\right.$ in blood (more than $\left.10 \mu \mathrm{g} / \mathrm{dl}\right)$

$$
\downarrow
$$

Lead $\left(\mathrm{Pb}^{2+}\right)$ ion diffuses across the blood brain barrier membrane

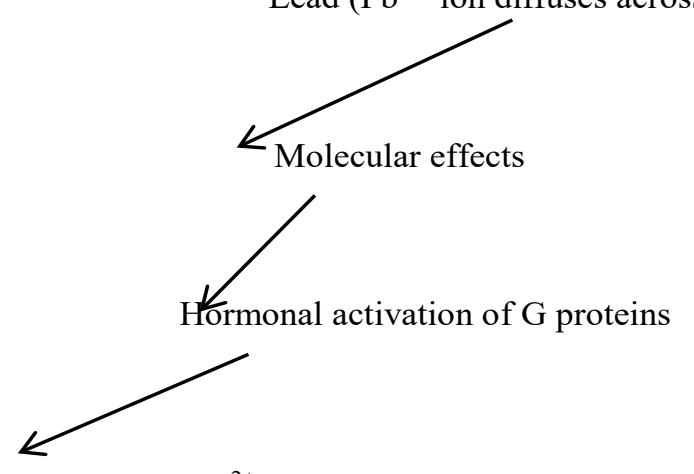

G-proteins opens $\mathrm{Ca}^{2+}$ channel which causes the release of $\mathrm{Ca}^{2+}$ from endoplasmic reticulum

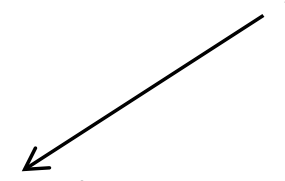

Entrance of $\mathrm{Pb}^{2+}$ into cells through calcium channel and binding with Calmodulin

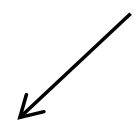

Series of cascade of reactions such as inflammatory process, muscle contraction, immune response, and nerve growth are pathologically activated. ATP utilization is increased.

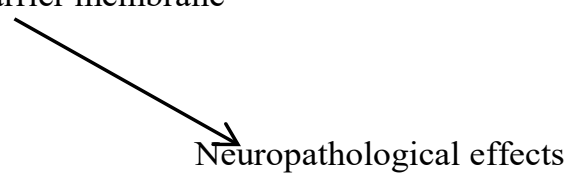

Lead disrupts communication between astrocytes and endothelial cells

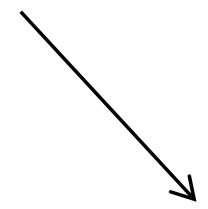

Movement of plasma into interstitial spaces

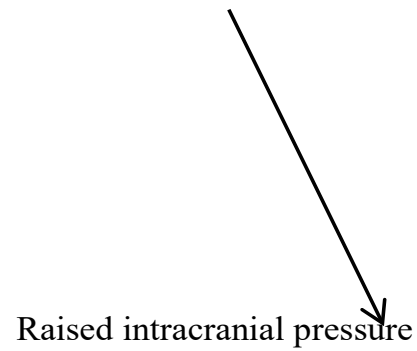

$$
\downarrow
$$

Development of edema and encephalopathy with an irreversible brain damage

Figure 1: Pathological process of accumulated Lead $\left(\mathrm{PB}^{2+}\right)$ in tissues and its organ system effects. Elevated levels of lead $\left(\mathrm{Pb}^{2+}\right.$ above $10 \mu / \mathrm{dl}$ moves across the blood brain barrier of the central nervous system, with consequently activating second messengers leading to release of $\mathrm{Ca}^{2+}$ on one hand. This promotes immune process and inflammatory process that with resultant destruction of neurons of the brain. On the other hand, movement of lead across the blood brain barrier causes a disruption in the architectural communication between the astrocytes and endothelial cells leading to encephalopathy and brain damage [13].

toxicity is an activational process of G-protein couple receptor with stimulation of calcium voltage gated channel. This action causes a release of stored $\mathrm{Ca}^{2+}$ in the endoplasmic reticulum [14]. In addition, this promotes the entrance and binding of $\mathrm{Pb}^{2+}$ with Calmodulin, $\mathrm{a}$ calcium sensor protein. Moreover, the displacement of calcium binding sites [15] leads to phosphorylation of protein kinases thereby causing gene transcription and enzyme activation, thereby causing more damaging effect on cellular tissues by activating inflammatory and immunological response as could be seen in Figure 1. Conversely, the neuropathological effect disrupts the neuronal cell tissue architecture of astrocytes and the endothelial cells. Edema of the brain and brain encephalopathy $[13,16]$ ensues due to movement of plasma into interstitial spaces leading to increased intracranial pressure, consequently resulting in brain damage. The effect of lead poisoning on the kidney is that 
of impairment of proximal convoluted tubule leading to aminoaciduria, glycosuria and hyperphosphaturia causing Fanconi syndrome in children [17]. The toxicity of lead affect negatively the metabolism of vitamins and these vitamins played an important role in growth and development of children.

\section{Effects of lead toxicity on various organ systems}

Recently, an acute exposure to high levels of lead has been shown to produce encephalopathy and neuropsychological deficits [18]. In pregnant women, the fetus astrocytes in utero are at a vulnerable high risk of lead intoxication because the immature endothelial cells that form the capillaries of the brain offer a much decreased resistance to lead, and thereby easily allow $\mathrm{Pb}^{2+}$ to enter the brain. Subsequently, intracellular lead $\left(\mathrm{Pb}^{2+}\right)$ replaces calcium as a second messenger, by binding with calmodulin more readily than calcium, which results in an alteration in the protein conformation (Figure 1) [18,19]. In pediatrics age group, gastrointestinal abdominal pain, anorexia, vomiting, and constipation are verycommon. Renal acute high-dose lead $\left(\mathrm{Pb}^{2+}\right)$ may cause proximal tubular dysfunction; with continued repetitive exposures, interstitial nephritis may also supervene. This may contribute to the onset and development of hypertension, especially with higher exposures.

Destruction of erythropoietin has been seen to contribute greatly to anemia. Hematologic lead poisoning chronically interferes with heme synthesis by inhibiting multiple enzymes ( $\delta$-aminolevulinic acid dehydratase and ferrochelatase) as shown in Figure 2

Glycine + Succinyl CoA
Aminolevunilinic acid synthase

Aminolevulinic acid

Porphobilinogen

Porphobilinogen deaminase

Hydromethylbilane

Uroporphyrinogen synthase

Uroporphyrinogen

Uroporphyrinogen decarboxylase

Coproporphyrinogen

Coproporhyrinogen oxidase

Protoporhyrinogen

$\downarrow$ Protoporphyrinogen oxidase
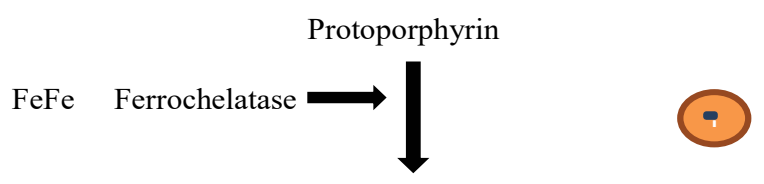

Heme

Figure 2: Biosynthesis of heme protein. The pathway illustrates heme synthesis inhibition by lead $\left(\mathrm{Pb}^{2+}\right) . \Delta$-amniolevunic acid synthase enzyme is inhibited leading to inability to synthesize aminolevulinic acid; a major precursor in the pathway. In addition, Ferrochelatase is inhibited with subsequent inability to add Iron to heme protein. Lead $\left(\mathrm{Pb}^{2+}\right)$ displaces $\mathrm{Fe}^{2+}$ from binding to protoporhyrin. 
thereby resulting in a microcytic anemia. Consequently, lead $\left(\mathrm{Pb}^{2+}\right)$ may also produce a hemolytic anemia with acute massive exposures [19].

Moreover, in endocrine leadprevents vitamin D conversion into its active form, 1,25 dihydroxy vitamin $D$, leading to impaired cell growth, maturation, and tooth and bone development in children [20]. This usually occurs in children only with high BLLs (> $62 \mu \mathrm{g} /$ $\mathrm{dL}$ ) whose nutritional deficiency is pronounced. Skeletal bone formation and bone resorption may be impaired; bone growth impairment and shortened stature may thus occur. An association between higher lead levels and adverse pregnancy outcomes has been made, but this is probably less significant at current lower environmental lead levels [21]. Prenatal exposure to low lead levels may increase the likelihood of prematurity and decreased birth weight [21]. Lead accumulation has been discovered with increase in age with time and with high propensity for intellectual disability $[2,22,23]$. The increase with age is probably due both to, the long skeletal half-life and higher environmental exposures in the past. In fact, age alone accounts for about half the variability in bone lead concentrations. Nevertheless, in the last 25 years, the blood lead concentration used to define poisoning or excessive exposure has fallen progressively from $40 \mathrm{pg} / \mathrm{dl}$ to $30 \mathrm{pg} / \mathrm{dl}$ to $25 \mathrm{pg} / \mathrm{dl}$, and finally to $10 \mathrm{pg} / \mathrm{dl}$. Usually, children with concentrations of $45 \mathrm{pg} / \mathrm{dl}$ or greater are treated with chelation therapy. Even though concentrations from $10 \mathrm{pg} / \mathrm{dl}$ to $44 \mathrm{pg} / \mathrm{dl}$ are indications of excessive exposure and toxic effects, children with concentrations in this range are generally not treated with drugs [11]. However, the chelating agents also have other adverse effects, with a great propensity for considerable nephrotoxicity. Here lies an obvious but important lesson to be learned from our past collective failure to appreciate the enormous health problems posed by lead. Lead is of great concern because it is both persistent in the environment and has a long biological half-life.

\section{Lead toxicity in oxidative phosphorylation}

Lead has been identified to impair electron transport chain in oxidative phosphorylation [24]. $\mathrm{Pb}^{2+}$ exposure in humans occurs mainly through air inhalation, food and water uptake which has been shown to be generally associated with numerous body functions such as the central and peripheral nervous systems, the red blood cells, the kidneys and the liver. It has been reported that the liver is the storage site and an important primary target in $\mathrm{Pb}^{2+}$ toxicity, and the hepatotoxicity of $\mathrm{Pb}^{2+}$ could be resulted from the impairment of the liver mitochondria [25]. Like in a research study carried out, several mitochondrial dysfunctions following the addition of $\mathrm{Pb}^{2+}(10-160 \mu \mathrm{M})$ were investigated.

It was found that $\mathrm{Pb}^{2+}$ inhibited the enzyme activities of mitochondrial respiratory complexes and complex III was the major source of $\mathrm{Pb}^{2+}$-induced significant reactive oxygen species (ROS) formation [26]. As a consequence, the results showed that $\mathrm{Pb}^{2+}$ induced significant progression in mitochondrial lipid peroxidation, adenosine triphosphate (ATP) consumption and glutathione (GSH) oxidationas it has been shown in Figure 3. In contrast, the cellular tissues are provided with defense mechanism with which the reactive oxygen species are mopped up, by enzyme systems including catalase, superoxide dismutase, glutathione peroxidase. On the other hand, $\mathrm{Pb}^{2+}$ induced marked changes in mitochondrial permeability transition (MPT) accompanied by mitochondrial swelling, mitochondrial membrane potential collapse, mitochondrial membrane fluidity decrease and cytochrome $c$ (Cyt $c$ ) release. In addition, several mitochondrial MPT inhibitors and chelators were utilized to determine the possible interaction sites of $\mathrm{Pb}^{2+}$ on mitochondria. In general,

Oxidative effect of lead $(\mathrm{Pb} 2+)$ on mitochondrial transport chain

$\begin{array}{ccccc}\begin{array}{c}\text { Complex I } \\ \text { NADH-ubiquinone } \\ \text { oxidoreductase }\end{array} & \begin{array}{c}\text { Complex III } \\ \text { Cytochrome b-c1 } \\ \text { complex }\end{array} & \begin{array}{c}\text { Complex II } \\ \text { Succinate } \\ \text { dehydrogenase }\end{array} & \begin{array}{c}\text { Complex IV } \\ \text { Cytochrome } c \\ \text { oxidase }\end{array} & \begin{array}{c}\text { ComplexV } \\ \text { ATP Synthase }\end{array}\end{array}$

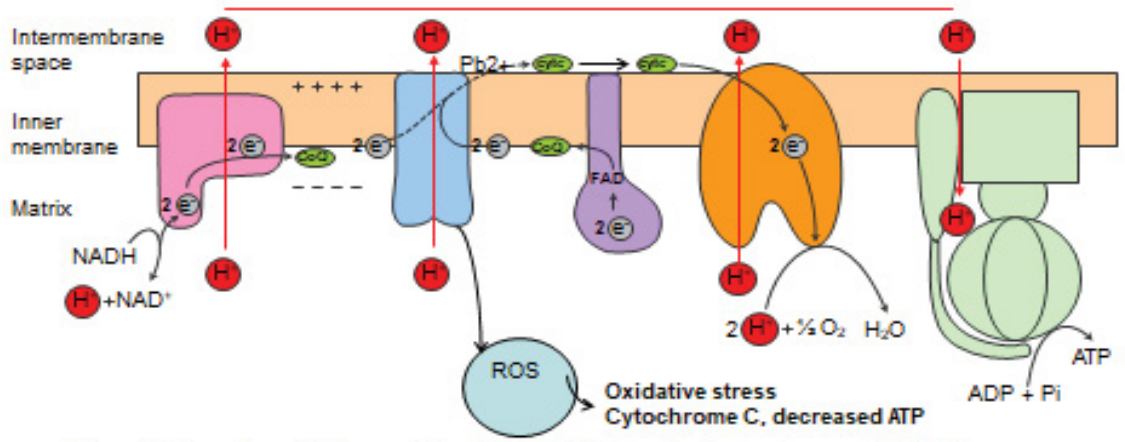

Figure 3: The schematic diagram of lead $\left(\mathrm{Pb}^{2+}\right)$ effect on the electron transport chain. Four complexes I, II, III, IV involved in the transport of electrons in the inner part of the mitochondrion to generate ATP. At complex III, electron transport is inhibited (broken lines) leading to decreased ATP, cytochrome $C$ release into the cytosol. The oxidative stress on the mitochondrion generates and accumulates reactive oxygen species (ROS), consequently damaging tissue protein and DNA of cells. 
the research data supported that the $\mathrm{Pb}^{2+}$-induced liver toxicity was a result of the disruptive effect on the mitochondrial respiratory complexes $[27,28]$.

\section{Anemia in lead poisoning}

Anemia is seen with children with lead poisoning and toxicity due to inhibition in the enzymes that catalyzes the synthesis of heme protein. Lead toxicity usually affects and inhibit ferrochalatase and d-aminoleuvinate dehydratase enzyme that catalyzes steps in the heme synthesis pathway (Figure 2) $[28,29]$. Investigative work done by Aub and colleagues pointed out the effect of lead on the osmotic fragility of red blood cell. These observations on the effects of lead on the osmotic fragility of the red cell have been almost unanimously been supported.

In contrast to the earlier work done, Sroczynski discovered that there is a decreased in resistance to hypotonic saline solutions after exposure of rabbits to acute and chronic lead solution [30] and found that red cells from both groups of animals showed a marked decrease in resistance to hypotonic saline solutions.

The increased hemolysis of the red blood due to $\mathrm{Pb}^{2+}$ poisoning results in weakness and fatigability in pediatric children [31]. There seems no doubt that lead has a profound effect on red cell precursors in the bone marrow, producing morphological changes and also causing defective haemoglobinization by inhibiting heme synthesis, and many other changes induced in the peripheral red cells could be the results of this primary action on erythroblastic cells in the bone marrow.

\section{Neurotoxicity in lead poisoning}

Lead toxicity is a life threatening disease condition that comes with multi-organ disorder. There is no safe blood lead level for children because of the growth and cognitive development of children in which lead toxicity tends to interfere with at this crucial stage of life. Neurological effect of lead poisoning in children during acute exposures to high levels coulddevelop into a condition referred to as encephalopathy and neurodegenerative diseases [32,33] (Figure 1). Lead exposure at low level has been proposed to cause other neuropsychologicaldeficits and lead induced hypertension [34-36]. Of great importance is the affection of the $\mathrm{Na}^{+} / \mathrm{K}^{+}$ATPase transport system that regulate the net movement of ions across the membrane channel $[37,38]$. Subtle, but convincing defects in cognitive function and behavior occur in children with blood levels of lead frequently encountered in the general populace [39-41].

However, the mechanisms by which lead disrupts brain function and the reasons for the apparent heightened sensitivity of the immature nervous system are not well understood. A potential biochemical site for the toxic action of lead is an area yet to be explored fully. At the cellular level of organization, the brain can broadly be divided into two components. The neurons with their processes and insulating myelin are the information system, while the endothelial cells and astrocytes that regulate the fluid environment within brain are the homeostatic system in function [42]. Neural networks are formed by interconnecting neurons with extensive processes consisting of dendrites that receive information from neurons and nerve endings that transmit information. In these networks, axons signal their targets (dendrites and neuronal cell bodies) by release of neurotransmitters from the presynaptic neuron fibers in response to an excitatory depolarization ofthe axonal membrane that is induced by action potential. Also, oligodendroglia cells surround the axons to form the myelin sheath, which acts to speed the wave of depolarization from the neuronal cell body to the nerve terminal [43]. The synergistic action of a nerve terminal and its receptor site on an adjacent neuron is termed a synapse. If low-level exposure to lead alters aspects ofbehavior, there must be a direct or indirect effect of the toxin upon the function of certain neural networks, and most importantly areas of the brain concerned with cognitive and behavioral functionand tendency to criminal conviction later in life [44-46]. By way of altering protein kinase-mediated control of cell function, lead $\left(\mathrm{Pb}^{2+}\right)$ could also disrupt the function of the homeostatic support system of the brain: The endothelial cells and the astrocytes [47]. The fluid environment of the nervous system is maintained under strict control by the blood-brain barrier. In contrast to other organs, the passage ofwater-soluble molecules between the blood and the brain fluid spaces do not occur by simple diffusion. Instead, selected molecules including the essential amino acids, glucose, calcium, sodium and potassium are transported across the capillary by means of carriers that are located in the plasma membrane of brain endothelial cells. These transport systems are highly specific and exclude most nonessential water-soluble molecules. Disruptions of this regulatory carrier protein promote neuronal cell damage with resultant neurological deficit.

\section{Lead poisoning and crime tendency in later future}

Lead as a neurotoxin has been well documented to be associated with criminal behavior [48-51]. There have been lines of evidence that have reported a correlation between blood lead level and crime conviction, due to insult and accumulating lead toxins to the neurons of the brain leading to development of antisocial behaviors and altered perspicacity during growth and developmental stage of life $[52,53]$.

\section{Biological effect of lead on metalloenzymes}

Lead poisoning has been shown to alter enzyme specificity and efficiency by displacement of the metal cofactors of different enzyme. Metallocarboxypeptidase 
is an enzyme with dual function of being an esterase and peptidase that uses zinc as co-factor [54]. Lead toxicity displaces the zinc as co-factor. The resultant effect of this is to produce metallocarboxypeptidase enzyme without peptidase function to degrade peptide bond with subsequent inhibition of protein metabolism.

\section{Laboratory investigation and clinical diagnosis of lead poisoning}

The whole blood specimens are usually collected by venipuncture using needles, disposable skin wipes, and blood collection tubes with anticoagulant. Blood lead level is still the gold standard to diagnosis of $\mathrm{Pb}^{2+}$ poisoning [55]. There are other workup plans that show an elevated $\mathrm{Pb}^{2+}$ in the blood and some tissues. They include Iron status, Zinc chelated protoporphyrin, renal and liver function test, complete blood count and in some cases radiographs' reading is being explored. A side from an elevated BLL, laboratory values in acute lead exposures will generally be normal. Measurement of increased quantities of heme precursors such as free erythrocyte protophorphyrin (FEP) level will also reflects impaired heme synthesis. As a consequence of bone marrow toxicity in children, a hypochromic, and microcytic anemia may be seen on full blood count (FBC) and basophilic stippling in red blood cells visualized on the peripheral blood smear. Radio-densities indicating growth arrest may be seen on radiographs of weightbearing surfaces of long bones. Abdominal radiographs are only useful to detect a recent ingestion of leaded paint chips or other lead-containing foreign bodies, which must be of sufficient size to be visualized [56]. In one of the studies conducted in a lead $\left(\mathrm{PB}^{2+}\right)$ poisoning clinic, children with elevated BLLs rarely had positive abdominal radiographs [57]. It is therefore assumed that repeated ingestion of paint chips can be detected if the timing of the radiograph is coincidental. In some instances, the kidneys may be damaged, resulting in an interstitial nephritis, resulting in abnormalities of renal indices of serum blood urea nitrogen and creatinine. Ahistory of eating lead-containing paint, together with gastro-intestinal symptoms, hyper-irritability, and weakness of the legs constitute a fairly typical presentation of chronic lead poisoning in childhood. The presence ofradio-opaque material in the abdomen, dense lines at the metaphysis of the long bones, anemia with basophilic stippling ofthe red cells, and marked coproporphyrinuria support this diagnosis in the patient with lead $\left(\mathrm{Pb}^{2+}\right)$ poisoning.

\section{Management}

Management of lead poisoning due to the ingestion of leaded paint chips or lead contaminated substance is dependent on whether it is acute or chronic. If radiological investigation of the abdomen reveals opacifications consistent with lead poisoning, gastrointestinal decontamination via whole bowel irrigation using polyethylene glycol electrolyte lavage solution is probably warranted without delay, as one of the general management protocol. Understandably, this procedure should be repeated until the abdominal radiographs are clear. After a child is diagnosed, based on clinical or laboratory parameters, with lead poisoning and has received adequate gastrointestinal decontamination, chelation may be required. In addition to gastrointestinal decontamination, chelation may effectively reduce the body lead burden and can be performed with multiple agents, such as Calcium disodium versenate, dimercaprol, D-penicillamine, and succimer (DMSA) [58]. Because these drugs comes with different risk; benefit profiles, varied routes of administration, and different protocols, necessitate physicians with experience in chelation therapy to be consulted prior to their implementation. In general, oral chelation agents (DMSA, penicillamine) are used for asymptomatic children with moderately elevated blood lead levels (BLLs) $(45-69 \mu \mathrm{g} / \mathrm{dL})[59,60]$. In children with higher blood lead levelor symptoms of lead toxicity, parenteral agents such as Calcium disodium versenate and dimercaprolare usually indicated individually or as a combinatorial therapy. Usually, the evidence that chronic lead exposure results in neurologic impairment, however, make it possible to recommend chelation therapy with the relatively benign chelating agent DMSA for many children with BLLs less than $45 \mu \mathrm{g} / \mathrm{dL}$. Of worth mentioning, these chelating agents are nonspecific in their metabolic activities; they bind and promote the excretion not only of lead $\left(\mathrm{Pb}^{2+}\right)$ but also of essential metals such as zinc and copper that are very important to the body system. They also have other adverse effects, with a great propensity for considerable nephrotoxicity. Here lies an obvious but important lesson to be learned from our past collective failure to appreciate the enormous health problems posed by lead. Despite the efficacy of DMSA in decreasing the body's total lead burden, the end point of therapy still remains a separate and unanswered issue in public health arena. The primary goal to limit lead-induced neurologic and developmental impairment in children is prevention. Once lead has entered the body, especially the skeleton, it is very difficult to remove due to increased biological half-life. For the majority of children, the success of treatment depends most heavily on identifying and eliminating the sources of lead exposure. Attempted modifications of children with hand-to-mouth and pica behavior may also be necessary. In addition, if significant quantities of lead are found in the home, lead abatement should be performed. There are many and different source of exposure of lead to human, but of great significant with high dose potential is the inhalational route of exposure.

\section{Result}

Lead as a poisonous environmental metal, has 
been proved to have harmful effect on various organs system of the body including, gastrointestinal system, immunological system, kidney and liver cell. In addition it primary organ of affection is the nervous system. The neurobehavioral changes found in lead-poisoned children may result from damage to the blood-brain barrier or direct effects of lead upon neuronal activity and synaptogenesis. A comprehensive investigation of these regulators should provide new insights into the biologic basis for the deficits that occur in children with low level exposure to lead. The sequelae of encephalopathy which include cerebral damage by lead poisoned children are of paramount concern. Reports also indicate a strong association between lead toxicity and crime conviction.

\section{Discussion}

Lead poisoning is posing a major health globally. According to the World Health Organization (WHO), lead poisoning is accounting for $0.6 \%$ of the global disease burden with an organization mission statement to be phased out by 2020. Definition of the interaction of lead $\left(\mathrm{Pb}^{2+}\right)$ with the binding of a neurotransmitter to cell surface receptors, the transduction process producing intracellular second messengers, the activation of specific protein kinases, and the alterations of cellular function and gene expression produced by phosphorylation of regulatory proteins (Figure 1), should be pursued for future investigational study. Most importantly, further research should be focused on therapeutic design of more effective chelating agents with less or no adverse effect that will be safe for this pediatric group. Children living in substandard housing are potentially vulnerable group because of comorbidities that may include poor nutrition and limited access to good health care services. Slum clearance might not be the least important way to solve the problem of lead poisoning. Clearing of old, dilapidated houses and providing modern low-cost housing should be the ultimate aim of the prevention program policy. Every large city should have a prevention program since the ultimate cost of lead poisoning is borne by the community in terms of wasted human resources, institutionalization of victims, and the resulting burdens on municipal health facilities and finances of every society.

\section{Conclusion and Future Direction}

Many developing countries in Africa are yet to come up with workable policy on preventive measures and approach to prevention of lead poisoning. Implementation of such policies will prevent the toxicity of lead among children. Through maximizing nutrition, and referrals to early intervention services that can help mitigate the impact of lead on intellectual development should be the priority. It is clear that efforts in some countries is quite commendable and have substantially reduced the overall amount of lead in the environment.
But then, lead poisoning still persist in different countries as a result of ingestion of lead-based paint chips and lead in toys [6]. Housing conditions in which leaded paint is still present must be properly abated to prevent ongoing exposure [61]. In addition, because low-level lead poisoning may be difficult to detect clinically, routine screening will help detect significant exposures long before overt clinical manifestations occur. Prevention should consist of several [62] coordinated actions: 1) Educational campaigns for health professionals and the public; 2) Case-finding and follow-up; 3) Implementation of meaningful law and legislation; 4) Research; and 5) Improved housing. Lead blood checkup should be considered among the routine laboratory check because of its human exposure by various activities of industries and soil contamination by waste products; which indirectly get consumed by human via farm produce. Educational programs for the medical profession including nurses and other health workers can be in the form of talks and exhibitions. Parents with young children should be informed of the hazards, sources, and methods by which lead poisoning occurs and the danger of pica. Perhaps local authorities should be encouraged to play a more positive role in the prevention of lead poisoning.

A well-informed public can take an active role in programs to reduce and eliminate lead poisoning. Logically, screening programs should be designed to detect lead in the domestic environment so that it may be removed before poisoning occurs in exposed children.

\section{Acknowledgement}

Not applicable.

\section{Ethical approval}

Not applicable.

\section{Conflict of Interest}

None declared.

\section{Funding}

Not applicable.

\section{References}

1. Evens A, Hyryhorczuk D, Lanphear BP, Rankin KM, Lewis DA, et al. (2015) The impact of low-level lead toxicity on school performance among children in the Chicago Public Schools: A population-based retrospective cohort study. Environ Heal 14: 21.

2. Lanphear BP, Hornung R, Khoury J (2005) Low-level environmental lead exposure and children's intellectual function: An international pooled analysis. Environ Health Perspect 113: 894-899.

3. Petit TL (1986) Developmental effects oflead: Its mechanism in intellectual functioning and neural plasticity. Neurotoxicology 7: 483-495.

4. Hauptman M, Bruccoleri R, Woolf AD (2017) An update on 
childhood lead poisoning. Clin Pediatr Emerg Med 18: 181 192.

5. Jacobziner H (1966) Lead poisoning in childhood: Epidemiology, manifestations and prevention. Clinical Pediatrics 5: 277-286.

6. Su M, Barrueto F, Hoffman RS (2002) Childhood lead poisoning from paint chips: A continuing problem. J Urban Health 79: 491-501.

7. Li MM, Cao J, Gao ZY, Shen XM, Yan CH (2015) The trend of lead poisoning rate in Chinese population aged 0-18-years-old: A meta-analysis. BMC Public Health 15: 756.

8. Rossi E (2008) Low level environmental lead exposure: A continuing challenge. Clin Biochem Rev 29: 63-70.

9. Pearson HA, Schonfeld DJ (2003) In: Rudolph CD, Lead. Pediatrics (21 $1^{\text {st }}$ edn), McGraw-Hill Professional.

10. Ragan $P$, Turner $T$ (2009) Working to prevent lead poisoning in children: Getting the lead out. JAAPA 22: 40-45.

11. Huang R, Ning H, Baum CR, Chen L, Hsiao A (2017) "What do you know?"-Knowledge among village doctors of lead poisoning in children in rural China. BMC Public Health 17: 895.

12. Memsadze K, Sanikidze T, Ratiani L, Gabunja L, Sharashenidze T (2009) Mechanisms of lead-induced poisoning. Georgian Med News 172-173: 92-96.

13. Brochin R, Leone S, Phillips D, Shepard N, Zisa D, et al. (2008) The cellular effect of lead poisoning and its clinical picture. The George Town Undergraduate Journal of Health Sciences 5: 2.

14. Habermann E, Crowell K, Janicki $P$ (1983) Lead and other metals can substitute for $\mathrm{Ca} 2+$ in calmodulin. Arch Toxicol 54: 61-70.

15. Toews AD, Kolber A, Hayward J (1978) Experimental lead encephalopathy in the suckling rat: Concentration of lead in cellular fractions enriched in brain capillaries. Brain Res 147: 131-138.

16. Marginean CO, Melit L, Moldovan HR, Lupu VV, Marginean MO (2016) Lead poisoning in a 16-year-old girl: A case report and review of the literature (CARE compliant). Medicine 95: e4916.

17. Bellinger D, Leviton A, Waternaux C, Needleman $H$, Rabinowitz M (1987) Longitudinal analyses of prenatal and postnatal lead exposure and early cognitive development. N Engl J Med 316: 1037-1043.

18. Simons TJB (1986) Cellular interactions between lead and calcium. Br Med Bull 42: 432-434.

19. Hegazy AA, Zaher MM, Abd el-hafez MA, Morsy AA, Saleh RA (2010) Relation between anemia and blood levels of lead, copper, zinc and iron among children. BMC Res Notes 3: 133.

20. Rahman A, Al Awadi AA, Khan KM (2018) Lead affects vitamin D metabolism in rats. Nutrients 10: 264.

21. Shannon M (2003) Severe lead poisoning in pregnancy. Ambul Pediatr 3: 37-39.

22. Miranda ML, Kim D, Overstree Galeano MA, Paul CJ, Hull AP, et al. (2007) The relationship between early childhood lead levels and performance on end-of-grade tests. Environ Health Perspect 115: 1242-1247.

23. Suk WA, Achanchian $\mathrm{H}$, Asante KA, Carpenter DO, Diaz Barriga F, et al. (2016) Environmental pollution: An under- recognized threat to children's health, especially in low-and middle-income countries. Environ Health Perspect 124.

24. Holtzman D, Hsu JS, Mortell P (1978) In vitro effects of inorganic lead on isolated rat brain mitochondrial respiration. Neurochem Res 3: 195-206.

25. Alexeyev MF (2009) Is there more to aging than mitochondrial DNA and reactive oxygen species? FEBS $\mathrm{J}$ 276: 5768-5787.

26. Ma L, Liu J, Dong J, Xiao Q, Zhao J, et al. (2017) Toxicity of $\mathrm{Pb} 2+$ on rat liver mitochondria induced by oxidative stress and mitochondrial permeability transition. Toxicol Res (Camb) 6: 822-830.

27. Knollmann-Ritschel BEC, Markowitz M (2017) Lead Poisoning. Acad Pathol 4: 2374289517700160.

28. Sroczynski J (1963) The hematopoietic system in rats in chronic lead poisoning. Postepy Hig Med Dosw 17: 585-594.

29. Flora G, Gupta D, Tiwari A (2012) Toxicity of lead: A review with recent updates. Interdiscip Toxicol 5: 47-58.

30. Vorvolakos T, Arseniou S, Samakouri M (2016) There is no safe threshold for lead exposure: A literature review. Psychiatriki 27: 204-214.

31. Reuben A (2018) Childhood lead exposure and adult neurodegenerative disease. J Alzheimers Dis 64: 17-42.

32. Bakuski KM, Rozek LS, Dolinoy DC, Paulson HL, Hu H (2012) Alzheimers's disease and environmental exposure to lead: The epidemiologic evidence and potential role of epigenetics. Curr Alzheimer Res 9: 563-573.

33. Horton CJ, Weng HY, Wells EM (2019) Association between blood lead level and subsequent Alzheimer's disease mortality. Environ Epidemiol 3: e045.

34. Yucebilgic G, Bilgin R, Tamer L, Tukel S (2003) Effects of lead on $\mathrm{Na}(+)-\mathrm{K}(+)$ ATPase and $\mathrm{Ca}(+2)$ ATPase activities and lipid peroxidation in blood of workers. Int $\mathrm{J}$ Toxicol 22: 95-97.

35. Weiler E, Khalil Manesh F, Gonick H (1988) Effects of lead and natriuretic hormone on kinetics of sodium-potassiumactivated adenosine triphosphatase: Possible relevance to hypertension. Environ Health Perspect 78: 113-117.

36. Shih RA, Hu H, Weisskopf MG, Schwartz BS (2007) Cumulative lead dose and cognitive function in adults: A review of studies that measured both blood lead and bone lead. Environ Health Perspect 115: 483-492.

37. Amato MS, Moore CF, Magzamen S, Imm P, Havlena JA, et al. (2015) Lead exposure and educational proficiency: Moderate lead exposure and educational proficiency on end-of-grade examinations. Ann Epidemiol 22: 738-743.

38. Canfield RL, Jusko TA, Kordas K (2005) Environmental lead exposure and childrens cognitive function. Riv Ital Pediatr 31: 293-300.

39. Fenga C, Gangnemi S, Alibrandi A, Costa C, Micali E (2016) Relationship between lead exposure and mild cognitive impairment. J Prev Med Hyg 57: E205-E210.

40. Bowman, PD, Ennis SR, Rarey KE, Betz AL, Goldstein GW (1983) Brain microvessel endothelial cells in tissue culture: A model for study of blood-brain barrier permeability. Ann Neurol 14: 396402.

41. Gebhart AM, Goldstein, GW (1998) Use of an in vitro system to study the effects of lead on astrocyte-endothelial cell interactions: A model for studying toxic injury to the blood-brain barrier. Toxicology and Applied Pharmaco 194: 191-206. 
42. Sanders T, Liu Y, Buchner V, Tchounwou B (2009) Neurotoxic effects and biomarkers of lead exposure: $A$ review. Rev Environ Health 24: 15-45.

43. Dribben WH, Creeley CE, Farber N (2011) Low level lead exposure triggers neuronal apoptosis in developing mouse brain. Neurotoxicol Teratol 33: 473-480.

44. Nina Pabello G, Bolivar V (2005) Young brains on lead: Adult neurological consequences. Toxicol Sci 86: 211-213.

45. Goldstein GW (1984) Brain capillaries: A target for inorganic lead poisoning. Neurotoxicology 5: 167-176.

46. Beckley AL, Caspi A, Broadbent J, Harrington BAH, Houts RM, et al. (2018) Association of Childhood Blood lead levels with criminal offending. JAMA Pediatr 172: 166-173.

47. Patrick $L$ (2006) Lead toxicity, a review of the literature. Part I: Exposure, evaluation, and treatment. Altern Med Rev 11: 2-22.

48. Nevin R (2000) How Lead Exposure Relates to Temporal Changes in IQ, Violent Crime, and Unwed Pregnancy. Environ Rese 83: 1-22.

49. Boutwell B, Nelson E, Emo B, Vaughn M, Schootman M, et al. (2016) The intersection of aggregate-level lead exposure and crime. Environ Res 148: 79-85.

50. Dietrich K, Douglas R, Succop P, Berger O, Bornschein R (2001) Early exposure to lead and juvenile delinquency. Neurotoxicol Teratol 23: 511-518.

51. Mielke H, Zahran S (2012) The urban rise and fall of air lead $(\mathrm{Pb})$ and the latent surge and retreat of societal violence. Environ Int 43: 48-55.
52. Chisolm IJ (1964) Childhood lead intoxication: A preventable summer disease. Pediatrics Digest 6: 29.

53. Somashekaraiah BV, Venkaiah B, Prasad AR (1990) Biochemical diagnosis of occupational exposure to lead toxicity. Bull Environ Contam Toxicol 44: 268-275.

54. Huttenlocher PR, Courten de C (1987) The development of synapses in striate cortex of man. Hum Neurobiol 6: 1-9.

55. Kim HC, Chae TJH, Choi W, Ye MHB, Kim B, et al. (2015) Evaluation and management of lead exposure. Ann Occup Environ Med 27: 30.

56. Katzung BG (2007) Basic and clinical pharmacology. McGraw Hill Professional.

57. Shannon MW, Townsend MK (2000) Adverse effects of reduce dose of penicillamine in children with mild-tomoderate lead poisoning. Ann Pharmacother 34: 15-18.

58. Binder S, Falk H (1998) Strategic planfor the elimination of childhood lead poisoning. Centers for disease control. American Journal of Public Health 88.

59. Felton D, Kelly Hoffman BS, Priddy D, Heu P (2019) The state of childhood lead poisoning prevention in Hawai i. Hawaii J Health Soc Welf 78: 320-323.

60. Moore MR (1975) Lead and Mitochondrial. Postgraduate Medical Journal 51: 760-764.

61. Haslam RHA (2003) Lead poisoning. Pediatr Child Health 8: 509-510.

62. Campbell C, Osterhoudt KC (2002) Prevention of childhood lead poisoning. Curr Opin Pediatr 12: 428-437. 